\title{
Effect of maternal diabetes and quercetin exposure on the oxidative stress and kidney damage in rat's fetus
}

\author{
Saeedeh Heidarinazhad1, Mahmood Khaksary Mahabady ${ }^{1 \star}$, Reza Ranjbar ${ }^{1}$, \\ Hossein Najafzadeh Varzi $^{2,3}$, Babak Mohammadian ${ }^{4}$, Mohammad Reza \\ Tabandeh ${ }^{5}$ \\ ${ }^{1}$ Department of Anatomy and Embryology, ${ }^{2}$ Department of Pharmacology, Faculty of Veterinary Medicine, Shahid Chamran \\ University of Ahvaz, Ahvaz, ${ }^{3}$ Molecular Biology Research Center, Health Research Institute, Babol University Medical Sciences, \\ Babol, ${ }^{4}$ Department of Pathology, ${ }^{5}$ Department of Biochemistry and Molecular Biology, Faculty of Veterinary Medicine, Shahid \\ Chamran University of Ahvaz, Ahvaz, Iran
}

*For correspondence: Email: mkhaksary@scu.ac.ir; Tel: +98-9131619252

\begin{abstract}
Purpose: To investigate the prophylactic effects of quercetin on oxidative stress and damage to kidney in rat's fetus harvested from diabetic mothers.

Methods: Female Wistar rats were divided to into four experimental groups: control, quercetin, diabetic, and quercetin-treated diabetic groups (6 rats in each group). Experimental diabetes was induced by intravenous injection of streptozotocin $(50 \mathrm{mg} / \mathrm{kg})$ and the female rats were mated with male rats. Thereafter, quercetin was orally administered by oral gavage (75 mg/kg), on 0, 7, 14 and 20 days of gestation. Foetuses were harvested on the 20th day of gestation and their kidneys, removed and the tissues examined biochemically and histopathologically. Subsequently, malondialdehyde (MDA) level, catalase (CAT), superoxide dismutase (SOD) and glutathione peroxidase (GSH-PX) activities were measured in the renal tissue.

Results: Maternal diabetes delayed fetal kidney development and renal tubular necrosis, and reduced the number of renal glomeruli, while quercetin decreased the level of these changes. Accordingly, the MDA level increased while catalase, superoxide dismutase and glutathione peroxidase activities decreased in diabetic fetal kidney. These biochemical changes were corrected by quercetin.

Conclusion: Quercetin has a protective effect on some biochemical and pathological changes in the kidney of foetuses exposed to maternal diabetes.
\end{abstract}

Keywords: Maternal diabetes, Streptozotocin, Quercetin, Renal teratogenicity, Fetus

\begin{abstract}
This is an Open Access article that uses a funding model which does not charge readers or their institutions for access and distributed under the terms of the Creative Commons Attribution License (http://creativecommons.org/licenses/by/4.0) and the Budapest Open Access Initiative (http://www.budapestopenaccessinitiative.org/read), which permit unrestricted use, distribution, and reproduction in any medium, provided the original work is properly credited.

Tropical Journal of Pharmaceutical Research is indexed by Science Citation Index (SciSearch), Scopus, International Pharmaceutical Abstract, Chemical Abstracts, Embase, Index Copernicus, EBSCO, African Index Medicus, JournalSeek, Journal Citation Reports/Science Edition, Directory of Open Access Journals (DOAJ), African Journal Online, Bioline International, Open-J-Gate and Pharmacy Abstracts
\end{abstract}

\section{INTRODUCTION}

Diabetes and high blood glucose, if not controlled, can cause long-term complications such as cardiovascular diseases along with pathological and functional disorders in the eyes, kidneys reproductive and nerves systems [1]. Diabetes is one of the most important pathological causes of the oxidative stress [2]. According to some previously-conducted 
research in this area, lipid oxidation and activities of superoxide dismutase, glutathione peroxidase and catalase enzymes were increased in the kidneys by diabetes. On the other hand, diabetes induced oxidative stress in all organs including kidneys [3]. Moreover, maternal diabetes mellitus was related to some developmental anomalies including in kidneys as shown in animals and human-related studies. The relationship between teratogenic effect, and free radicals, and oxidative stress has been reported in several studies $[4,5,6]$. In addition, it was reported that oxidative stress and free radicals caused nephropathy, and tubular apoptosis and damaged podocytes and glomeruli in diabetic conditions [5].

Some studies have shown that the teratogenic effects of diabetes can be minimized by the application of antioxidant drugs. The activities of antioxidant enzymes such as catalase and GPX in the kidney of diabetic rats were decreased by utilizing of Alpha-lipoic acid and vitamin C [6].

Quercetin is one of the most frequently studied flavonoids, which are abundant fruits and vegetables that eliminate free radicals by binding with hydrogen and oxygen radicals to prevent peroxidation lipids and cell death oxidative damages [7]. This flavonoid has been evaluated in various experimental diabetic studies; for example, some research investigated that the preventive effect of quercetin in the hyperglycemia condition which is induced by streptozotocin along with reduced oxidative stress and increased antioxidant enzyme activity [8]. On the other hand, it was reported that the administration of quercetin was decreased the oxidative stress caused by alloxan-induced diabetes in mice [9].

In this study, the effects of maternal diabetes on fetal kidney malformations in and its relationship with oxidative stress using an experimental animal model were evaluated. Moreover, the role of quercetin in the prevention of fetal malformations in kidney tissues and corresponding changes of oxidative stress factors were studied histologically.

\section{EXPERIMENTAL}

\section{Animal study and experimental design}

In order to induce the diabetes in rats; streptozotocin (Sigma -Aldrich) was intravenously injected (50 mg/kg of rat's weight) $[10,11]$. Subsequently, the blood glucose was measured after a week using a glucometer and via tail vein blood samples. The wistar rats with the blood glucose levels higher than $250 \mathrm{mg} / \mathrm{dl}$ were considered as diabetic rats. The study was approved by the Ethical Review Committee, Faculty of Veterinary Medicine, Shahid Chamran University of Ahvaz, Iran (approval ref no. EE/95.6.29/9525695). The experimental procedures were performed according to the guiding principles of the Institute for Laboratory Animal Research in Guide for the Care and Use of Laboratory Animals [12].

For mating, each female rat was subjected to a male one. When a vaginal plug was found in the evening of the following day, the copulation day as zero day gestation. The pregnant rats were kept separate in the four groups of the same conditions, diet, environmental humidity, and temperature $\left(23 \pm 2^{\circ} \mathrm{C}\right)$ and drugs were administered as follows:

Normal saline was orally administered (control group) to healthy pregnant rats of the first group on $0,7,14$, and 20 days of gestation. Quercetin (Sigma-Aldrich) was administered by gavage (75 $\mathrm{mg} / \mathrm{kg}$ ) to healthy pregnant rats in the second group on $0,7,14$, and 20 days of gestation (control group) [13]. Normal saline was orally administered to pregnant diabetic rats of the third group on $0,7,14$, and 20 days of gestation (diabetic control group); Quercetin was administered by gavage $(75 \mathrm{mg} / \mathrm{kg}$ ) to pregnant diabetic rats in the fourth group on $0,7,14$, and 20 days of gestation (diabetes group treated with quercetin).

On the $20^{\text {th }}$ day of gestation (a few hours after the last injection), rats were euthanized and then the foetuses were removed. Thereupon, the left and right fetal kidneys were immediately removed. The right kidney of fetus was placed in $10 \%$ buffered formalin to prevent cellular changes resulting from autolysis and cell corruption. Left kidney was stored at -70 for later evaluation of the oxidative stress status.

\section{Pathological studies}

The right fetal kidney samples were fixed in $10 \%$ buffered formalin solution. Fixed samples were dehydrated in aggraded series of alcohols, cleared in xylene, embedded in paraffin, and cut with microtome at 5 to $6 \mu \mathrm{m}$. The sections were mounted on glass slides, deparaffinized and stained with Haematoxylin and Eosin (H \& E) for light microscope observations [14]. The Pathological studies were done using digital Dino-Lite lens and Dino-capture 1 software (AnMo Electronics Corp., New Taipei City, Taiwan). In order to count the number of glomeruli and necrotic tubules in each group, 5 
slides were prepared and investigated in 5 different fields at $40 x$ magnification.

\section{Measurement of oxidative stress and antioxidant indices}

Frozen tissues (left kidneys) were rapidly thawed and homogenized with a homogenizer (Heidolph, Germany) in cold phosphate buffer ( $\mathrm{pH} 7.4$ ) in a ratio of 1:10. Then, the supernatant was removed through centrifugation at $10,000 \mathrm{rpm}$ for $10 \mathrm{~min}$ at $4^{\circ} \mathrm{C}$ (Centrifuge $5415 \mathrm{R}$; Eppendorf AG, Hamburg, Germany) for subsequent analyses. The protein content of the supernatant was determined using the Bradford method with bovine serum albumin as a standard protein. The activities of GPx and SOD were evaluated using commercial kits (Randox, UK), according to the manufacturer's instructions. The catalase activity was measured as described previously, in which the homogenized tissue was incubated with $\mathrm{H}_{2} \mathrm{O}_{2}$ while the reaction was stopped by adding ammonium molybdate solution [15]. Moreover, the intensity of the yellow complex formed of molybdate and $\mathrm{H}_{2} \mathrm{O}_{2}$ was measured at $410 \mathrm{~nm}$ and the enzymes activities were expressed as $\mathrm{IU} / \mathrm{mg}$ protein.

Lipid peroxidation was quantified by measuring the formation of thiobarbituric acid reactive substances (TBARS) [14]. For a short time, 0.2 $\mathrm{ml}$ tissue homogenate added to $0.8 \mathrm{ml}$ of a solution containing $15 \%(\mathrm{w} / \mathrm{v})$ TCA, $0.375 \%(\mathrm{w} / \mathrm{v})$ thiobarbituric acid, and $0.25 \mathrm{~N} \mathrm{HCL}$. Then the protein precipitant was removed by centrifugation at $5000 \mathrm{rpm}$ for $5 \mathrm{~min}$. The supernatants were transferred to glass test tubes containing $0.02 \%$ $(\mathrm{w} / \mathrm{v})$ butylated hydroxytoluene and heated for 15 min at $100^{\circ} \mathrm{C}$ in a boiling water bath, then cooled and centrifuged at $2000 \mathrm{rpm}$ for $5 \mathrm{~min}$ to remove the precipitant. On the other hand, the absorbance was measured at $532 \mathrm{~nm}$ using spectrophotometer (Bio-RAD Model 680) and thiobarbituric acid levels were expressed as $\mathrm{nmol} / \mathrm{mg}$ protein.

\section{Statistical analysis}

The results are reported as the mean \pm SEM. Statistical significance between groups was determined using SPSS (Version 16; SPSS Inc., Chicago, USA) and compared via one-way ANOVA followed by LSD post hoc comparisons. Mean difference was statistically considered significant at $p \leq 0.05$.

\section{RESULTS}

In the microscopic examination, it was observed that in fetal kidney tissues of the control group were completely undeveloped and they contained more embryonic connective tissues. Moreover, the external coating process of simple squamous cells of Bowman's capsule was not developed. As a result, it can be said that the differentiation was not complete though development continued. Although, in all foetuses of the control group (Figure 1, Figure 2 and Figure 3 ) and the groups being treated with quercetin (Figure 2) though no specific lesion was observed in proximal and distal renal tubules. The periglomerular space along with proximal and distal renal tubules were not different in their appearance. Moreover, kidney tissues and texture were normal.

The nephrogenesis in fetal kidneys of the diabetic group delayed more than the others (Figure 2 and Figure 3 ). In addition, among the diabetic samples, the least focal necrosis was observed in the diabetic group which had received quercetin (Figure 2 and Figure 3). The numbers of necrotic tubules were counted in the treated and non-treated diabetic groups and their mean ( \pm standard error) obtained as were 11.40 \pm 1.66 and $7.20 \pm 0.86$, respectively, which indicated a statistically significant difference $(p$ $=0.02$ ). The tubular necrosis was not observed in the non-diabetic groups. Furthermore, the increased periglomerular space was observed among $10 \%$ of the diabetic kidney samples.

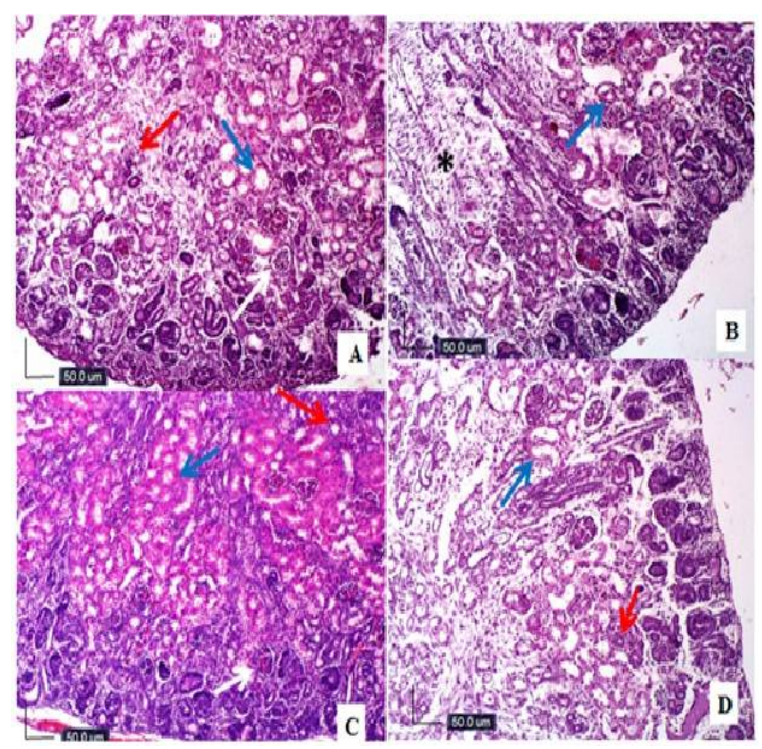

Figure 1: Kidney tissues of fetal rats $\left(20^{\text {th }}\right.$ day) in the studied groups (10x, H \& E). Control (A), Diabetic (50 $\mathrm{mg} / \mathrm{kg} / \mathrm{iv}$ ) (B), Quercetin (75 mg/kg/gavage) (C), and Diabetic $(50 \mathrm{mg} / \mathrm{kg} / \mathrm{iv})$ treated by quercetin (75 $\mathrm{mg} / \mathrm{kg} / \mathrm{gavage}$ ) (D). Fewer number of tubules and renal glomeruli is quite evident. *Fetal kidney tissues; blue arrow: proximal urinary tubules, red arrow: distal tubules 

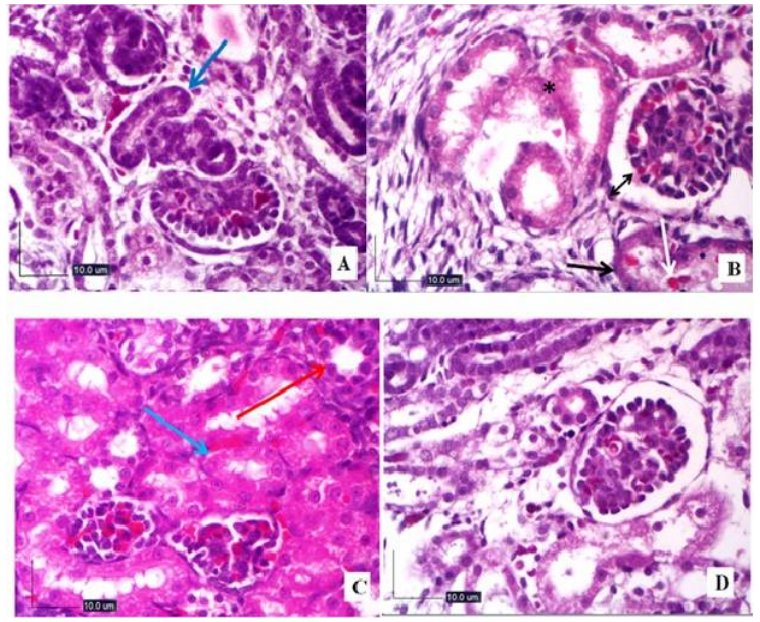

Figure 2: Kidney tissues of fetal rats $\left(20^{\text {th }}\right.$ day $)$ in the studied groups (40x, $\mathrm{H} \quad$ \& $\quad \mathrm{E})$. Control (A), Diabetic (50 mg/kg/iv) (B), Quercetin (75 $\mathrm{mg} / \mathrm{kg} / \mathrm{gavage}$ ) (C), and Diabetic (50 mg/kg/iv) treated by quercetin (75 mg/kg/gavage) (D). Blue arrow: the proximal urinary tubules, the black arrow: the tube containing urinary tubules that contains red blood cells and the destruction damaged renal glomeruli, white arrow: red blood cells; * Tubular necrosis; double arrow: increase periglomerular space

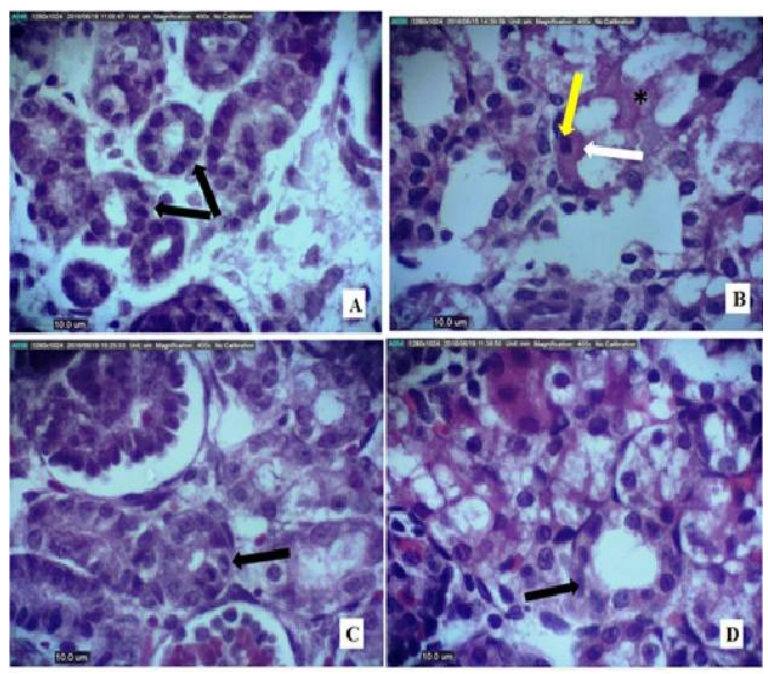

Figure 3: Histopathological changes in the renal tissues of fetal rats $\left(20^{\text {th }}\right.$ day) in the groups studied (40x, H \& E). Control (A), Diabetic (50 mg/kg/iv) (B), Quercetin (75 mg/kg/gavage) (C) and Diabetic (50 $\mathrm{mg} / \mathrm{kg} / \mathrm{iv}$ ) treated by quercetin ( $75 \mathrm{mg} / \mathrm{kg} /$ gavage) (D). ${ }^{*}$ Renal tubular necrosis includes pyknotic nuclei (yellow arrows) and acidophilic cytoplasm of necrotic cells (white arrow), and proximal tubules (black arrow)

The glomeruli were counted at 5 fields of the microscope in each group and their means in the control, quercetin, diabetic and quercetin-treated diabetic groups were $9 \pm 1.22,9.4 \pm 1.34,6 \pm$ $0.7,8.4 \pm 0.87$, respectively. The number of glomeruli significantly was fewer in the diabetic groups than the non-diabetic groups (Figure 4).

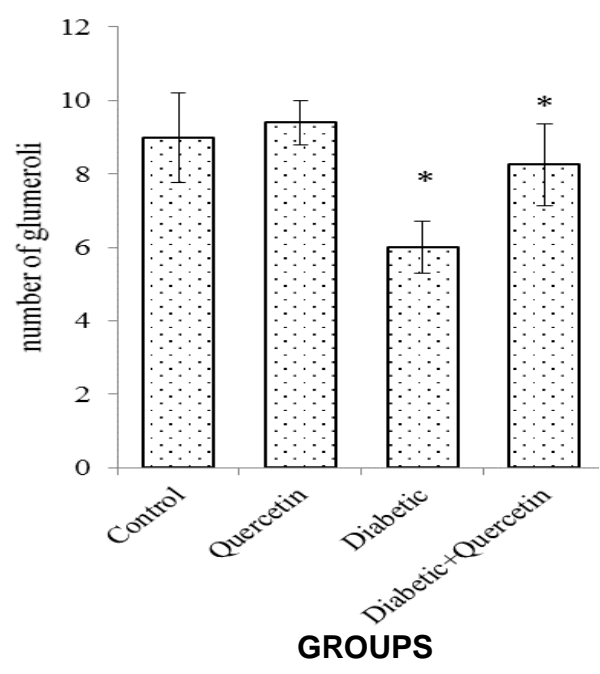

Figure 4: The number of renal glomeruli in studied groups (mean \pm SEM). * Values significantly varied between the diabetic and non-diabetic groups

MDA level in fetal kidneys increased significantly in the non-treated diabetic group and quercetin treatment prevented it. The SOD activity in the fetal kidneys decreased significantly in the nontreated diabetic group while quercetin treatment prevented it. However, the SOD activity in the control group was significantly higher than that of the other groups. Statistical analysis of the enzyme activity (GPX) in the studied groups under study revealed that the induction of diabetes reduced GPX activity in the renal tissues of diabetic fetus unlike others, and treatment with quercetin intensified the activity of GPX. The catalase activity significantly decreased in the non-treated diabetic group and quercetin treatment prevented it. Quercetin increased the catalase activity in the non-diabetic rats (Table 1).

Table 1: MDA level and SOD, GPX, and catalase activity in renal tissues

\begin{tabular}{|c|c|c|c|c|}
\hline Group & $\begin{array}{c}\text { MDA } \\
\text { (nmol/mg } \\
\text { protein) }\end{array}$ & $\begin{array}{c}\text { SOD } \\
\text { (IU/mg } \\
\text { protein) }\end{array}$ & $\begin{array}{c}\text { GPX } \\
\text { (IU/mg } \\
\text { protein) }\end{array}$ & $\begin{array}{c}\text { Catalase } \\
\text { (IU/mg } \\
\text { protein) } \\
\end{array}$ \\
\hline U & \multicolumn{4}{|c|}{$0.92 \pm 0.104 .28 \pm 0.17 a 4.75 \pm 0.69 b 1.05 \pm 0.02 b$} \\
\hline Quercetin & \multicolumn{4}{|c|}{$0.68 \pm 0.083 .56 \pm 0.49 \mathrm{~b} 6.74 \pm 0.41 \mathrm{a} 1.21 \pm 0.06 \mathrm{a}$} \\
\hline Diabetic & \multicolumn{4}{|c|}{$1.76 \pm 0.23 a 2.54 \pm 0.21 \mathrm{c} 2.04 \pm 0.21 \mathrm{c} 0.77 \pm 0.05 \mathrm{c}$} \\
\hline $\begin{array}{l}\text { abetic + } \\
\text { ercetin }\end{array}$ & \multicolumn{4}{|c|}{$0.83 \pm 0.043 .25 \pm 0.27 b 3.83 \pm 0.35 b 1.08 \pm 0.01 b$} \\
\hline
\end{tabular}

Lower case alphabets in each column indicate significant $(p \leq 0.05)$

\section{DISCUSSION}

In this study, the protective effect of quercetin was evaluated in terms of histopathological changes and oxidative stress in fetal kidneys based on the experimental diabetic model. The results showed that maternal diabetes in 
pregnancy increased the severity of histopathological changes and oxidative stress indices. Treatment with quercetin corrected these changes.

In similar previous studies, the protective effects of quercetin were well-documented. It was reported that quercetin administration $(15 \mathrm{mg} / \mathrm{kg}$ ) for three consecutive days, prevented hyperglycemia induced by streptozotocin, reduced the oxidative stress, and increased the antioxidant enzyme activity [8]. Furthermore, Orsolic et al demonstrated that intraperitoneal administration of $50 \mathrm{mg} / \mathrm{kg}$ quercetin for 7 consecutive days protected animals from oxidative stress caused by alloxan diabetes in mice [9].

The increase in ROS levels caused damage to proteins, lipids, and DNA due to increase in oxidative stress in particular conditions such as diabetes mellitus. This will continue dynamic decreases in the system [16]. It was shown that enzymes activities such as catalase, GPX decreased in the kidneys of diabetic rats; however, using of alpha-lipoic acid and vitamin $\mathrm{C}$ increased the activity of these enzymes [6]. Glutathione peroxidase (GSH-Px) is an enzyme defense mechanism, including biological membranes and other components of a cell that protects cells against the oxidative damage [17].

It was reported that the kidney function reduced in the diabetic rats. Moreover, the expression of SOD and the catalase activity decreased in the diabetic rats, while the using alcoholic extract of Vitex doniana leaves increased the activity of these enzymes [18]. The result of another study was showed that hyperglycemia in diabetic mice increased the oxidative stress; however, selenium prevented oxidative stress and tissue damages [19]. In this study, diabetes caused dilation of the urinary space and the nephrogeneis delay. The number of tubular necrosis in the diabetic control group was higher than quercetin-treated diabetic group. The quercetin with antioxidant properties could prevent the effect of diabetes on the rat's fetus.

In similar studies, the role of antioxidants in reducing diabetes-related malformations has been considered. Other studies reported that diabetes impairs kidneys and taking antioxidants can prevent these changes. Similarly, it was revealed that vitamin $\mathrm{E}$ and $\mathrm{C}$ can reduce changes in the glomerular structures caused by diabetes, which confirm the results of this study [20]. Histopathological damages in experimental diabetic mice including glomerulosclerosis and connective tissue replacement by tubules resulted in damaged kidney tissues and the presence of denominated lymphocytes in renal interstitial cells [21]. Moreover, damaged cells and destruction of the cortex along with proximal and distal tubules, as well as the increase in the space between the tubular were reported in the kidney tissues of diabetic rat [22]. To date, many studies on the mechanism of diabetes mellitus and its effect on nephropathy have been conducted recently [23].

In a study, considering the results of experimental diabetes [23], the effects of vitamin $E$ and quercetin on the morphologic alterations of kidneys in the rats treated with cyclosporine $A$ were investigated, the results of which showed that the treatment with vitamin $E$ along with quercetin prevented severe damage, moderate and mild renal tubules, corresponding with the results of experimental diabetes [24]. Moreover, quercetin reduced the inflammation of the kidneys in the diabetes induced by streptozotocin in rats [25]. Likewise, it was shown that the administration of quercetin decreased the cell damage induced by cisplatin in the urinary tubules in rats [26]. Although the provirus research studies the effect of protective quercetin on teratogenic features of diabetes, the results of this study highlight the fact that is required more studies for a more accurate evaluation of its effect on drugs, especially with respect to the existence of interfering factors.

\section{CONCLUSION}

The role of quercetin in eliminating teratogenic effects of diabetes is here reported for the first time. Experimental diabetes can causes fetal anomalies including kidney damage but these changes are ameliorated by quercetin. On the other hand, diabetes increases MDA level but decreases antioxidant enzyme activities in fetal kidneys. Thus, quercetin has a protective effect on some biochemical and pathological changes in kidney foetus harvested from diabetic mothers.

\section{DECLARATIONS}

\section{Acknowledgement}

The Vice-President of Research at Shahid Chamran University of Ahvaz is appreciated for funding this study.

\section{Conflict of interest}

No conflict of interest is associated with this work. 


\section{Contribution of authors}

The authors declare that this work was done by the authors named in this article and all liabilities pertaining to claims relating to the content of this article will be borne by them.

\section{REFERENCES}

1. Gispen WH, Biessels GJ. Cognition and synaptic plasticity in diabetes mellitus. Trends in Neurosciences 2000; 23: 542-549.

2. Punithavatki VR, Anuthama R, Prince PS. Combined treatment with naringin and Vitamin $C$ ameliorates streptozotocin induced diabetes in male Wistar rats. $J$ Appl Toxicol 2008; 28: 806813

3. Prakasam A, Sethupathy $S$, Puqalendi KV. Antiperoxidative and antioxidant effects of Casearia esculenta root extract in streptozotocin-induced diabetic rats. Yale J Biol Med 2005; 78(1): 15-23.

4. Fisher JC, Kling DE, Kinane TB. Oxidation-reduction (redox) controls fetal hypoplastic lung growth. J Surg Res 2002; 106: 287-291.

5. Jung DS; Li JJ, Kwak SJ, Lee SH, Park J, Song YS, Yoo TH, Han SH, Lee JE et al. FR167653 inhibits fibronectin expression and apoptosis in diabetic glomeruli and in high-glucose stimulated mesangial cells. Am. J. Physiol. Renal Physiol 2008; 295: 595-604.

6. Sadi G, Eryilmaz N, Tutuncuoglu E, Cingir S, Guray $T$. Changes in expression profiles of antioxidant enzymes in diabetic rat kidneys. Diabetes Metab Res Rev 2012; 28(3): 228-235.

7. Lee J, Hahm ER, Singh SV. Withaferin A inhibits activation of signal transducer and activator of transcription 3 in human breast cancer cells. Carcinog 2010; 31(11): 1991-1998.

8. Abdelmoaty MA, Ibrahim MA, Ahmed NS, Abdelaziz MA. Confirmatory studies on the antioxidant and antidiabetic effect of quercetin in rats. Indian Journal of Clinical Biochem 2010; 25(2): 188-192.

9. Orsoloic N, Gajski G, Garaj-Vrhovac V, Dikic D, Prskalo $Z S$, Sirovina D. DNA-protective effects of quercetin or naringenin in alloxan-induced diabetic mice. European $J$ Pharmacol 2011; 656:110-118.

10. Uriu-Hare Stern JS, Keen CL. Influence of Maternal Dietary Zn Intake on Expression of Diabetes-Induced Teratogenicity in Rats. Diabetes 1989; 38(10): 12821290.

11. Volpato GT, Calderon IMP, Sinzato S, Campos KE, Rudge MVC, Damasceno DC. Effect of Morus nigra aqueous extract treatment on the maternal-fetal outcome, oxidative stress status and lipid profile of streptozotocin-induced diabetic rats. J Ethnopharmacol 2011; 138: 691- 696 .

12. Institute for Laboratory Animal Research: Guide for the Care and Use of Laboratory Animals. Eighth Edition, The National Academies Press, Washington, DC. 2011
13. Liang C, Oest ME, Jones JC, Prater MR. Gestational high saturated fat diet alters C57BL/6 mouse perinatal skeletal formation. Birth Defects Research (Part B) 2009; 86: 362-369.

14. Bancroft JP, Gamble M. Theory and practice of histological techniques. 5th edition, Churchill Livingstone: 2002; 125-130.

15. Bavari M, Tabandeh MR, Najafzadeh Varzi $H$, Bahramzadeh S. Neuroprotective, antiapoptotic and antioxidant effects of I-carnitine against caffeine-induced neurotoxicity in SH-SY5Y neuroblastoma cell line. Drug Chem Toxicol 2016; 39(2): 157-66.

16. Zaken $V$, Kohen $R$, Ornoy $A$. The development of antioxidant defense mechanism in young rat embryos in vivo and in vitro. Early Pregnancy 2000; 110-123.

17. Zago M, Patriciai O. The antioxidant properties of zinc: interactions with iron and antioxidants. Free Radic Biol Med 2001; 31(7): 266-274.

18. Yakubu OE, Ojogbane E, Nwodo OC, Naneri-Chidozie VO, Dasofunjo K. Effect of Vitex doniana ethanol leaf extract on renal function in diabetic rats. European $\mathrm{J}$ Experiment Biol 2013; 3(3):630-634.

19. Reddy KG, Stehno-bittel L, Hamada S, Enwemeka CS. The biomechanical integrity of bone in experimental diabetes. Diab Res Clin Prac 2001; 54(1): 1-8.

20. Ganesh E, Chowdhury A, Malarvani T, Vardhan NA. Microscopical observation of kidney for ameliorative effects of Vitamin- $E$ and $C$ in streptozotocin- induced diabetic rats. Int J Life Sci Pharma Res 2012; 3(2): 135143.

21. Zafar M, Naqvi NH, Ahmed M, Kaimkhani ZA. Altered Kidney Morphology and Enzymes in Streptozotocin Induced Diabetic Rats. Int J Morphol 2009; 27(3): 783790

22. Azemi ME, Namjoyan F, Khodayar MKH, Ahmadpour F, Darvish Padok A, Panahi M. The Antioxidant Capacity and Anti-diabetic Effect of Boswellia serrate Triana and Planch Aqueous Extract in Fertile Female Diabetic Rats and the Possible Effects on Reproduction and Histological Changes in the Liver and Kidneys. Jundishapur J Nat Pharm Prod 2012; 7(4): 168-175.

23. Stanton T. Oxidative stress and diabetic kidney disease. Current Diabetes Reports 2011; 11: 330-336.

24. Mostafavi pour Z, Vessal M, Zal F, Khoshdel Z, Torabinejad S. Protective Effects of Vitamin $E$ and/or Quercetin Co-Supplementation on the Morphology of Kidney in Cyclosporine A-Treated Rats. Iran J Basic Med Sci 2009; 34 (4): 1-6.

25. Wang Y-H, Chao PDL, Hsiu SL, Wen KC, Hou YC. Lethal quercetin-digoxin interaction in pig. Life Sci 2004; 74(10): 1191-1197.

26. Davi PS, Shyamala Davi CSD. Protective effect of quercetin in cisplatin-induced cell injury in the rat kidney. Indian J Pharmacol 1999; 31:422-442. 